\title{
Political Mediation in Nuclear Waste Management: a Foucauldian Perspective
}

\author{
Erik Laes $^{1}\left(\mathbb{D} \cdot\right.$ Gunter Bombaerts $^{1}$
}

Received: 13 October 2020 / Accepted: 4 May 2021 / Published online: 11 August 2021

(c) The Author(s) 2021

\begin{abstract}
This paper aims to open up high-level waste management practices to a political philosophical questioning, beyond the enclosure implied by the normative ethics approaches that prevail in the literature. Building on previous insights derived from mediation theory (in particular the work of Verbeek and Dorrestijn), Foucault and science and technology studies (in particular Jasanoff's work on socio-technical imaginaries), mediation theory's appropriation of Foucauldian insights is shown to be in need of modification and further extension. In particular, we modify Dorrestijn's figure of "technical determination of power relations" to better take into account the (literal and figurative) aspects of imagination, and complement Dorrestijn's work with the figures of techno-scientific mediation, and the inherently political figures of socio-technical and state-technical mediation, both based on Foucault's notion of governmentality. Our analysis implies that the practical implementation of a highlevel nuclear waste (HLW) management strategy will require the "stitching together" of these different mediations, which is an inherently political task.
\end{abstract}

Keywords Foucault $\cdot$ Mediation theory $\cdot$ Nuclear waste $\cdot$ Power

\section{The Missing Political Dimension in the Philosophy of High-Level Waste Management}

As expressed by international or supranational organizations such as the International Atomic Energy Agency (IAEA, 2011) and the OECD Nuclear Energy Agency (OECD-NEA, 1995, 2007), a strong consensus has by now been established among nuclear industry actors that the best management option for nuclear high-level waste

Erik Laes

e.j.w.laes@tue.nl

Gunter Bombaerts

g.bombaerts@tue.nl

1 Philosophy \& Ethics Group, Department of Industrial Engineering and Innovation Sciences, Eindhoven University of Technology, PO Box 513, 5600 MB Eindhoven, Netherlands 
(HLW) (from both a technological and moral point of view) is geological disposal. ${ }^{1}$ The general idea of geological disposal is to construct an underground facility located somewhere in a stable and suitable geological layer (e.g., clay, salt domes, granite), to fill it up with waste packages, to backfill the galleries and shafts, and, ultimately, to close, seal, and forget the repository (IAEA, 2018). HLW management has attracted a fair amount of scrutiny from philosophers and ethicists of technology, in particular in discussions related to intergenerational ethics (Gosseries, 2005; Taebi, 2012; Kermisch \& Taebi, 2017; Tondel \& Lindahl, 2019). These philosophical contributions have invariably adopted the perspective of epistemology or normative ethics. From this perspective, the question is raised whether, from an epistemological point of view, the scientific arguments in favor of specific HLW management options (geological disposal in particular) live up to the universal standards of sound science (see, e.g., the seminal Shrader-Frechette, 1993), or whether, from a normative ethics point of view, the justification of different HLW management options can stand the test of intergenerational justice or sustainability assessment frameworks (Kermisch \& Taebi, 2017; Taebi \& Kloosterman, 2008). Taebi and Kloosterman (2008), for instance, approach the question whether or not to recycle spent fuel from nuclear reactors by using an overarching intergenerational justice framework to elucidate the extent to which these two options succeed in securing sustainable development for present and future generations, in terms of guaranteeing resource availability, health and environmental safety, and security (i.e., guaranteeing the non-proliferation of nuclear materials for military purposes). Typically, normative ethics approaches different options for managing HLW as technological artifacts that have impacts on society, seeing it as its task to guide decision-makers in choosing the best option, or at least in making explicit the value trade-offs involved in choosing one option over the other, independent of societal or political contexts. As we will show in Section 6, this search for universal normative principles comes at the price of abstraction and simplification. It tends to lose sight of the inherently political presuppositions in the presumably "a-political" philosophical frameworks or reflections on technology.

To develop this political perspective on technology, we use the work of Michel Foucault and mediation theory as our key references. ${ }^{2}$ Foucault's refusal to adopt the position of a "universal intellectual" speaking truth to power based on transcendental

\footnotetext{
${ }^{1}$ A major environmental concern related to the production of nuclear power is the creation of radioactive wastes such as uranium mill tailings, spent (used) reactor fuel, and other radioactive wastes (e.g., arising from the reprocessing of spent fuel). Radioactive wastes are subject to special regulations that govern their handling, transportation, storage, and disposal in order to protect human health and the environment. These regulations are based on the radiological properties and potential hazards of the radioactive waste in question. Radioactive waste is generally classified as "very low-level waste," "low-level waste," "intermediate-level waste," or "high-level waste." High-level waste is the most difficult to handle and manage, because the materials within this classification can remain radioactive and dangerous to human health and the environment for thousands (or in the case of some radio-isotopes even millions) of years.

${ }^{2}$ Other examples that deviate from the universalist perspective (not explicitly drawing upon the work of Foucault) are Poirot-Delpech and Raineau (2016), who develop an anthropological perspective on the different dimensions of time involved in developing a geological repository in France, and Schröder (2016), who draws upon insights from science and technology studies (STS) to advance an interpretation of the development of geological disposal as a form of social experimentation.
} 
principles makes his work particularly interesting for our purposes. He even once famously defined philosophy as "the politics of truth," in the sense that "the role of philosophy is that of showing the knowledge effects produced by the struggles, confrontations and battles that take place within society" (Foucault, 2012, p. 3). Although Foucault himself has never developed a philosophy or ethics of technology, recent work in mediation theory has appropriated certain aspects of Foucault's methodology for questioning contemporary technological developments (Bergen \& Verbeek, 2020; Dorrestijn, 2012; Verbeek, 2011). Mediation theory's core tenetthat technologies help to shape the relations between human beings and the world (or society) — corresponds on a fundamental level with Foucault's relational ontology of power, in which technology plays a crucial mediating role. Like Foucault, mediation theory approaches technologies not as material "objects" opposed to human "subjects," or as mere instrumental extensions of human beings, but rather sees them as mediators of human-world relations (Verbeek, 2011, 2013). The use of Foucault's methodology makes it possible to enrich mediation theory with concepts that explain the fundamental interdependence between power practices and processes of subjectivation. Hence, this appropriation of the Foucauldian method by mediation theory offers us a good starting point to develop the political perspective we need for our research. However, we will show how the incorporation of Foucauldian insights in mediation theory has so far been based on a selective reading. Partly, this is due to the fact that mediation theory typically restricts its analyses to the mediation between individual technological artifacts and individual users. To be sure, there are some recent openings created from within mediation theory to start the reflection on "democratizing technology," but this reflection so far has only led to the somewhat vague advise to open up the public sphere to a "free and open" discussion about the forms of the "good life" enabled by new technologies (Verbeek, 2013). Though helpful, this recommendation prompts further questions such as how precisely this "opening up" should be conceived in a context of power imbalances, whether such "free dialogue" is possible and how it should be conceived of, and how a political theory of mediation could be helpful in pinpointing the political dimensions of technologies.

Though a full treatment of these questions is beyond the scope of a single article, we aim to take the first steps in the direction of a political extension of mediation theory by confronting it with the inherently political technology of HLW management.

Our main contribution to the literature lies in the addition of new figures of technological mediation as revealed through an elaboration of the key Foucauldian methodological concepts of a "technological-political scheme," the "conduct of conduct," and "state reason" based on our case analysis of the Belgian HLW management program. ${ }^{3}$ Case material has been drawn from available public resources (referenced in the text) and additional informative interviews with six key experts with different institutional backgrounds. Informed by this empirical investigation, we also show how a political questioning of present HLW management practices inspired by Foucault could have practical consequences for political action.

\footnotetext{
${ }^{3}$ For a more in-depth overview and discussion of this program, we refer the reader to Schröder et al. (2015).
} 
Our paper is structured as follows. First, we briefly review the existing incorporation of Foucault's methodology in mediation theory (Section 2) before using the existing incorporation (with one small modification) as an interpretative lens to question the broad spectrum of HLW management practices (Section 3). In the following sections of the paper, we adopt the full scope of Foucault's political methodology (parts of which have so far been overlooked in mediation theory) to engage with our empirical case. Through our empirical investigation, we show how mediation theory can be further enriched with three different forms of political subject/ object constitution. In the techno-scientific mediation, a subject-witness to the eternal truth of geological disposal's functioning is positioned alongside geological disposal as a passive technology favoring forgetting (Section 4). In the socio-technical mediation, a responsible collective (made up of engineers and concerned publics) is constructed alongside geological disposal as an active engineering object in a process of continuous and iterative improvement (Section 5). Finally, in the statetechnical mediation, a subject of state reason (raison d'état) is positioned alongside objectified stakeholder categories and values (Section 6). Our analysis therefore reveals the inherently and deeply political character of managing HLW, since the three forms of subject/object constitution cannot be reconciled under one overarching universal perspective. Section 7 concludes with a discussion of the theoretical and practical policy implications of our analysis.

\section{Mediation Theory's Selective Appropriation of Foucault}

Even though the philosophy or ethics of technology was never the main theoretical concern for Foucault, the use of notions such as "technique" or "technology" is pervasive throughout his work. This fact has of course not gone unnoticed, with some key references now available that contribute to the exegesis of the Foucauldian conceptualization of technology (e.g., Behrent, 2013; Gerrie, 2003). Foucault has been introduced into the philosophy of technology by scholars working in the field of mediation theory (Bergen \& Verbeek, 2020; Dorrestijn, 2012; Verbeek, 2011). In particular, Dorrestijn (2012) draws upon the middle Foucault, using Surveiller et punir (Foucault, 1991) as a key reference to identify two figures of technological mediation, and upon the later Foucault's methodological insights on the fashioning of the self, using Histoire de la sexualité, Vols. II \& III (Foucault, 1990, 1992) as key references to develop an ethics of technology that focuses on taking care of the quality of the interactions between human beings and technology. Mediation theory's close alignment with science and technology studies (STS), also one of the key disciplines involved in the setting up of radioactive waste governance processes (Barthe, 2009; Jasanoff \& Kim, 2009; Solomon et al., 2010) (cf. Section 5), further adds to the relevance of this theoretical perspective for our paper. In the remainder of this section, we limit our discussion to the elaboration of the two figures of technological mediation drawn from Surveiller et punir, since the second part of Dorrestijn's article (on the ethics of technological mediation) is exclusively concerned with how individuals govern and fashion themselves in their daily lives through their engagements with contemporary "technologies of the self" (such as, e.g., smartphone apps 
or other persuasive technologies in general), thereby omitting the political dimension of these engagements. ${ }^{4}$

The two figures of technological mediation drawn from the application of the genealogical method as explained in Surveiller et punir are called the "training of technically mediated routines" and the "technical determination of power relations." The first of these figures is derived from Foucault's detailed descriptions of the "microphysics of disciplinary power" in various institutions such as factories, hospitals, schools, the military, and prison. The disciplining power technique is about situating individuals in a particular space (e.g., that of the factory or clinic) so that all their movements over time can be carefully directed, observed, and corrected. In order to achieve a sufficient degree of efficiency, it is necessary that an at first unfamiliar action sequence is consciously practiced by going through successive training schedules, ultimately resulting in an internalized routine (e.g., practicing the exactly right position to use a pencil in schools or a rifle in the army). Dorrestijn's (2012) representation of this form of disciplinary power is faithful to Foucault's original, but through his exclusive focus on Surveiller et punir as key reference, he omits other forms of the exercise of power that Foucault introduces in later works. In particular, the concept of a "governmentality," mainly developed over the period 1978-1980 (cf. Foucault, 2007, 2008), cannot be overlooked as a figure for the exercise of political power through techniques other than disciplinary ones, aimed at producing docile political subjects. As set out by Foucault, governmentality should be understood as the set of techniques for constructing collectives out of individuals whereby the whole is greater than the sum of the constituent parts (e.g., the collective becomes representative of an entire subset of society through statistical classification, or it comes to represent a "responsible public" by participating in public hearings). It concerns a series of techniques, procedures, institutions, and calculations with which an authoritative institution tries to steer the conduct of individuals or collectives; in more concise terms, governmentality can be defined as "the conduct of conduct" (Foucault, 1982, p. 220). We will return to this issue in Section 5, where we discuss the specific form of governmentality at play in the socio-technical mediation of HLW management.

The second figure ("technical determination of power relations") is based on Foucault's discussion of the Panopticon (Dorrestijn, 2012, pp. 228-229). Dorrestijn arrives at this designation on the basis of the observation that constructing disciplinary institutions (e.g., schools, clinics, prisons) according to the methodological principles of "panoptic design" is a necessary and sufficient condition for certain power effects to take place (hence, the use of the notion of "technical determination"). In our opinion, however, here Dorrestijn's reading of Foucault is a bit too

\footnotetext{
${ }^{4}$ In a more recent article that uses both Foucault and Levinas to enrich mediation theory, this "Foucauldian problematic" is mentioned in the following terms (though not further analyzed) in the context of a smartphone app that makes use of gamification to steer behavior: "First, some worry that gamification is often used, not as part of Foucaultian practices of freedom, but rather to subtly predict, control, and steer behavior of users based on a behaviorist, dopamine-driven account of humanity. Engaging in a 'gamified life' would normalize this reductive anthropology and teach users to abide by and habituate a set of implicit but nevertheless imposed rules. In other words, gamification may represent a seductive form of Foucaultian biopolitics" (Bergen \& Verbeek, 2020).
} 
deterministic. As Foucault (1991, p. 202) himself contends, the Panopticon should not only be understood as an architectural principle guiding the construction of buildings, but rather also as the diagram of a power mechanism reduced to its ideal form. Stripped of any obstacle, resistance, or friction, its functioning may be imagined as a purely architectural and optical system, but it should equally be understood as a political-technological figure, which can and must be seen apart from each specific application. Following this clarification, we propose to rename the second figure of technical mediation as "technology as imagination," thereby capturing the two aspects implied by Foucault's discussion of the Panopticon, namely, the idea that this form of technical mediation should be understood as a "politicaltechnological figure" or "diagram of a power mechanism reduced to its ideal form" (hence, as an "image-ination" in a literal sense-i.e., the making of an image), and the idea that under this form of mediation technology is able to capture the imagination of those in power. As such, "technology as imagination" holds within itself a potential power-i.e., a promise that certain practical effects can be actualized in reality provided that spaces are ultimately configured as prescribed by the imagination. Unlike "discourses" or "discursive frames," "technology as imagination" as we define it (based on Foucault) is directly associated with active practices of power, such as the selection of development priorities, the allocation of funds, the investment in material infrastructures, and the designation of relevant publics. The crucial importance of imagination in technological mediation has been extensively analyzed by STS scholars Jasanoff and Kim (2009). ${ }^{5}$ These authors coin the notion of "sociotechnical imaginaries," defined as "...collectively imagined forms of social life and social order reflected in the design and fulfilment of nation-specific scientific and/ or technological projects..." (Jasanoff \& Kim, 2009, p. 120), which aligns very well with our notion of "technology as imagination." In what follows, we further specify the functioning of these (amended and complemented) figures of mediation in Dorrestijn (2012) in the context of HLW management, starting with the central role of the imagination of "forgetting-by-not-showing" that provides the cornerstone for the elaboration of the entire HLW management program.

\section{Imaginations of Containing Nuclear Waste}

Jasanoff and Kim (2009) provide a useful lead for identifying the imaginations at work in HLW management. Discussing nuclear power programs in the USA and South Korea, they identify a specific form of imaginary at work, which they label "Containing the Atom." Put very briefly, the positive and negative aspects of nuclear power support each other in a kind of double-bind situation: the more and the stronger the negative aspects can be separated and kept contained (first and foremost in the collective imagination), the more and the stronger the positive aspects will stand out. Conversely, contamination between the two categories must be avoided at all cost in order to guarantee the viability of nuclear power programs as such.

\footnotetext{
5 Jasanoff and Kim (2009, p. 122) also refer to Foucault's Surveiller et punir in elaborating on their concept of socio-technical imaginaries.
} 
Jasanoff and Kim (2009) see this logic of containment paradigmatically articulated in president Dwight Eisenhower's “Atoms for Peace" speech in 1953. Applying this logic of containment to the case of nuclear waste management, we first need to underline the crucial role played by the notion of exclusion. In nuclear waste management, a strict distinction is made between two categories of radioactive materials: materials that have a useful application in the economic sense and materials that fall outside the "useful application" category. ${ }^{6}$ Interestingly, the exclusion logic also implies a strict division of responsibility for nuclear materials: as long as these materials have a useful application, they fall under the responsibility of (usually) private energy market players (i.e., electricity producers), while the management of the useless (the radioactive waste) falls under the responsibility of one public actor (namely, NIRAS/ONDRAF). The transfer from one category to another is based on the initiative of the private players (they have to judge when the material no longer serves them and can therefore be declared to be waste) and has to respect certain regulatory requirements (e.g., with regard to the required quality of waste packaging). The strict dichotomy between the useful and the useless feeds the imagination of a cleansing - an imagination that can only be sustained by making it plausible that contamination certainly cannot occur between the two categories. The question is of course: how can the imagination of "containment-as-cleansing" take on a convincing shape?

The most convincing form of strict purification is, of course, firstly to ensure that the category of the useless simply disappears entirely in a physical sense-either by removing nuclear waste far from us or by physically destroying it. The possible launching of HLW into space-an option that was intensively explored in the early years of the nuclear industrial era (in the 1950s) but abandoned because of economic costs and risk concerns - is an example of such a removal strategy. ${ }^{7}$ The research in the area of thorough separation and treatment of long-lived radioactive materialsthe so-called partitioning and transmutation (P\&T) - is an example of an attempt to physically destroy the long-lived waste. This strategy has so far proved unsuccessful, but its appeal in capturing imagination is still evident from the ongoing international research programs in that field (see, e.g., the MYRRHA research project undertaken by the Belgian nuclear research center). ${ }^{8}$ However, in the absence of a reliable disappearance strategy, nuclear waste management policy must resort to a second option: if the existence of the waste cannot be undone, at least care must be taken that the waste does not show itself to us. This "showing itself" refers to both the physical display of the radiation emitted by the waste and its manifestation in a psychological sense-in terms of fear of the radiation. Only what does not appear, and what will not appear in

\footnotetext{
6 This distinction is usually enshrined in law; for instance in Belgium, according to Article 1 of the Royal Decree of 30 March 1981 determining the NIRAS/ONDRAF's tasks and modalities, radioactive waste is defined as "... any substance for which no use is foreseen and which contains radionuclides in a concentration higher than the values that considers the competent authority [sic] to be acceptable for substances that may be used or discharged without supervision" (quoted in NIRAS/ONDRAF, 2011, p. 24).

7 For low- and intermediate-level waste, ocean dumping according to the maxim "the solution to pollution is dilution" was common practice until it was banned in 1993 under the London Convention. Ocean dumping of high-level waste was banned in 1972.

8 https://www.sckcen.be/en/projects/myrrha (accessed on 17 April 2020).
} 
the future, can and should be forgotten with any peace of mind. This is the fundamental logic at work here, which finds its technical embodiment in geological disposal. Without the imagination of "forgetting-by-not-showing," talk of a "solution" to the problem of HLW would simply not be possible. It is the teleological end point of the three further forms of mediation that will be introduced in Sections 4-6, which all contribute in a specific way to the further operationalization of this imagination.

However, before continuing our argumentation in the following sections, we would briefly like to quote the third-and also least preferred-exclusion strategy. If the nuclear waste cannot be prevented from showing up, then the logic of exclusion requires at least that its manifestation be subject to strict monitoring and regulation. An accurate register of nuclear waste must be kept at all times, different types of waste must be identified, radiation must be accurately measured, regular checks on the integrity of waste packaging must be carried out, etc. This third exclusion strategy finds its technical counterpart in the temporary storage and monitoring of nuclear waste as it currently takes place, for example, at the sites of the nuclear power stations in Doel and Tihange in Belgium, or the perpetual long-term storage in a central location that NIRAS/ONDRAF discusses (and ultimately rejects) as an option in its waste plan.

\section{Techno-scientific Mediation: Geological Disposal as a Technology of Forgetting}

In the absence of possibilities for purification through destruction or physical removal, and to put an end to the situation of weak purification in which the manifestation of nuclear waste is only curtailed by strict monitoring and regulation, NIRAS/ONDRAF follows the international consensus in choosing geological disposal-the technical incarnation of the imagination of "forgotten-by-not-showingup"- as the reference solution and end point of the Belgian HLW management program. Research on geological disposal of HLW started early in Belgium. As far back as 1974, detailed investigations started concentrating on the so-called Boom clay layer-a geological layer with promising characteristics, conveniently located at a depth of around $220 \mathrm{~m}$ under the site of the Belgian nuclear research center (SCK•CEN) in Mol. In 1980, the construction of an underground research laboratory (named HADES) in the Boom clay layer commenced, the first of its kind worldwide. Although geological disposal in Boom clay has been the reference scenario from the start of Belgian HLW management research and dedicated research has steadily continued, up until today, no formal political decision has been taken. The status at the time of writing this paper (September 2020) is that the Belgian nuclear waste management organization NIRAS/ONDRAF has submitted (on 15 April 2020) a strategic waste management plan for public consultation ${ }^{9}$ expressing

\footnotetext{
9 As required by Council Directive 2011/70/Euratom of 19 July 2011 establishing a Community framework for the responsible and safe management of spent fuel and radioactive waste, EU Member States need to submit such a strategic plan to the European Commission. The plan can be downloaded from the following websites: https://www.niras.be/sea2020 (in Dutch) or https://www.ondraf.be/sea2020 (in French).
} 
a preference for geological disposal (at an as yet unspecified location in Belgium) to a round of public consultations, after which a government decision is expected to follow.

Following our Foucauldian line of questioning, embodied in the adaptation of Dorrestijn's second figure of technological mediation, in this section, we analyze how the technological imagination of geological disposal gives rise to a particular regime of truth, defined by Foucault $(2012$, p. 94) to "designate the set of processes and institutions by which, under certain conditions and with certain effects, individuals are bound and obliged to make well-defined truth-acts." Of course, it is not enough that political decision-makers adhere to a certain technological imaginary for it to become true. The fact that Foucault, when studying phenomena such as madness, criminality, or sexuality, always analyzes power and knowledge in its complex interdependencies does not imply that knowledge should be seen as merely instrumental to the exercise of power. The truth effects of knowledge always potentially exceed what is strictly needed for the exercise of power, hence the need for a constant renegotiation between these two factors. Applied to our topic, we therefore ask ourselves how "the truth" about geological disposal (i.e., knowledge about its functioning in the distant future) is able to mediate power effects (i.e., contributes to its implementation in reality), and how a subject capable of operationalizing this truth is constructed as a corollary.

For an answer to this Foucauldian question, we need to look beyond Foucault, however. Throughout his oeuvre, Foucault is concerned with investigating powerknowledge complexes in the broad context of "subjectivation"-i.e., processes by which individuals are constituted (e.g., by disciplinary power) or constitute themselves (e.g., by techniques of the self) as subjects. As a consequence, Foucault's focus on the knowledge side of the power-knowledge complex is exclusively on the human sciences (e.g., criminology, psychology, psychiatry), while his focus on the power side is on rules, methods, or techniques for steering one's own conduct or the conduct of others. Foucault himself never analyzes "hard" or applied sciences and their relation to technological artifacts or programs. As a consequence, we need to turn our attention to the literature on techno-scientific mediation for further guidance. Here, we can fruitfully draw on the work of Bensaude Vincent and Loeve (2018). According to these authors, what sets apart techno-scientific mediation from purely scientific mediation is the fact that the former form of mediation is not so much concerned with representing the world but rather with intervening in it. Techno-scientific research is "mainly oriented toward design; and as research in a design mode, technoscience is most adequately characterized as an exploration of nature's capacities, whereby nature is reconfigured as a field of possibilities" (Bensaude Vincent \& Loeve, 2018, p. 176). Its priority is not to discover the laws of nature (i.e., the fundamental constraints that condition the behavior of objects in nature), but rather the "potentialization of nature" (i.e., the possible behavior of natural objects within the limits given by the laws of nature).

Referring back to our case, the fundamental design perspective underlying geological disposal is to have any release from the artificial barriers of the waste packaging and the underground installation be delayed and further diluted by the selected geological host formation for a sufficiently long time period to let radioactive decay 
occur naturally (this process can take thousands to even millions of years for some radio-isotopes) (IAEA, 2018). The international nuclear expert community explicitly frames geological disposal as a "permanent and final solution" (OECD-NEA, 1995, 2007) whose safety, after closure of the facility, does not depend on the presence of man (ICRP, 2013). Geological sciences (hydrogeology, geochemistry, seismology, etc.) are enlisted to deal with the kind of cosmic/geological time dimensions implied by the reliance on geological disposal. They enable the techno-scientific community involved in furthering the cause of geological disposal to operationalize the truth about geological disposal by simply letting the technical processes occurring underground "speak for themselves" in an act of demonstration (Sundqvist \& Elam, 2010a, b), while eliminating the need for any speculations regarding future human interactions with the technology (i.e., the temptation to ask questions such as "How are future generations likely to perceive and interact with a geological disposal facility?"). The techno-scientific subject "projects" itself, so to speak, into this non-symbolic, purely operative space of naturally occurring processes. This is done, for instance, by relying on natural analogues (i.e., showing how similar geological layers have evolved over time under the influence of events such as ice ages or flooding) or experiments on more limited timescales combined with mathematical modelling. Based on mathematical equations that simulate the dispersion of radioisotopes in the geological layers, it is graphically possible to estimate the maximum exposure of people and the environment to radiation over periods of hundreds of thousands of years.

The specific form of subjectivity mediated by geological disposal is, however, paradoxical: the natural and material processes active deep underground can never really "speak for themselves" as, inevitably, the scientific community must engage in a hermeneutical effort to deliberate on the validity of their models. After all, safety cases for geological disposal based on modelling rely on various assumptions and scenarios. Trust in the results of the models used therefore boils down to trust in the scientific community developing and using these models (Silvast et al., 2020): have the best models available really been used? And can the necessary simplifications that always form the basis of mathematical models be justified considering the real complexity of the geological reference concept? Observations of this kind have, for instance, led the members of the International Commission on Radiation Protection (ICRP, 1997) to conclude that long-term risk calculations are fundamentally unreliable for predictive purposes (p. 11) and that the role of such estimations is to provide an indication or illustration rather than a prediction of the robustness of the disposal system (p. 29).

For a better understanding of this techno-scientific mediation, it is also crucial to note that even though geological disposal is at heart a geo-engineering project, the specific subjectivity mediated by its design is at odds with the subjectivity mediated in standard engineering practices. The aim of constructing a mathematical model representing the functioning of a geological disposal over thousands or even millions of years is to show that such technology is possible. Such a form of proof manifests a capacity and opens up a possible future, but from a strictly engineering point of view, the status of this type of knowledge amounts (at best) to a proof of concept. As pointed out by Davis (2019), even 
though the use of models is part and parcel of standard engineering education and practices, follow-up and monitoring of technologies up to the end of their lifetime once they become embedded in society is an equally important constituent part of engineering practices. Davis' observation serves to underscore the crucial difference between geological disposal and more ordinary technologies such as bridges, cars, or microwave ovens: whereas any other technology can be recalled in the event that it does not function properly (there are technicians who have the necessary knowledge to repair or possibly replace the malfunctioning technological artifact), this is excluded by design in the case of a geological repository. Deep geological layers function as the ultimate safety barriers, and future generations are not allowed to meddle with these layers for whatever reason. In this sense, a geological repository is an absolute technology-absolute, because it can no longer be questioned from a specific (historical, geographical, cultural) context. The question whether it functions properly, or what prompted us (the postwar generations) to use this technology, or the technology that created the wastes in the first place (i.e., nuclear power), can simply no longer be asked. In the case of geological disposal, this dialogue with future generations is simply precluded, even at the imaginary level. Hence, the technological mediation at work in geological disposal subjectivates current publics by making them witness the "proof of concept," while future generations will be confronted with "absolute technology." Understanding this form of mediation is only possible by modifying Dorrestijn's second figure of technological mediation into "technology as imagination" and extending it to include techno-scientific mediation.

\section{Socio-technical Mediation: Implementation of Geological Disposal as a Process of Stepwise Decision-Making}

Continuing our line of investigation, Foucault not only emphasizes how technology works on the level of an imagination-i.e., the idea that technology should be analyzed as a "political-technological figure" or "diagram of a power mechanism reduced to its ideal form" (cf. Section 3) — but he also stresses that technology plays an important role in teaching new ways of thinking and practical routines (i.e., Dorrestijn's mediation figure "training of technically mediated routines"). In the process of applying concrete technologies, not only a form of objective practical knowledge is created, but also a new subject-namely, a subject who becomes aware of his/ her new skills throughout the process. In other words, and applied to our case, the imagination of "forgetting-by-not-showing" underlying the geological disposal project does not simply work at an ideological level, but has to be fed by its practical implementation. In this regard, it is important to note that the political decision in favor of geological disposal that NIRAS/ONDRAF is pushing for would mean the start of a phased development that would take several decades to complete since, according to the most favorable forecasts, the construction of a geological repository would take at least 20-30 years. Taking into account the fact that irradiated fuel elements have to cool down for about 50-80 years before they can be placed in a deep clay layer, the last waste packages resulting from Belgian nuclear power 
production could in any case only be disposed of around 2075 at the earliest. ${ }^{10}$ This entire period will involve a process of developing, testing, and improving specific engineering solutions leading to the ultimate implementation of a geological repository on Belgian soil, such as the choice of a host formation, the choice of possible host zones, the choice of one or more host sites, the choice of materials for constructing waste containers, and the choice of backfill material for the waste galleries (NIRAS/ONDRAF, 2011).

Can this implementation phase, between the taking of a government decision in favor of geological disposal and the final closure of the repository, be adequately described in terms of standard engineering practice as set out in the previous section? Not quite. Even though with the publication of its Waste Plan NIRAS/ ONDRAF is primarily aiming at political approval of its preference for geological disposal as the technological solution to pursue for HLW management, the agency is also actively constructing a decision-making strategy involving different publics to be followed in the coming decades. ${ }^{11}$ The process of stepwise decision-making advocated by NIRAS/ONDRAF leaves open the precise duration of different phases in the implementation of geological disposal and the outcome of decisions about which options to take and when. Public consultation and formal political decisions are required to move the process from one phase or activity to another. As explained by one of our interviewees (a safety assessor and developer of the long-term safety strategy for HLW management), this approach is very much inspired by the Canadian approach of "adaptive phased management," described by Durant (2009, p. 898) as a "...process of continuous learning, an acknowledgment of inevitable technical uncertainties, a commitment to allow citizens an active role in decision-making, while neither promoting nor penalizing decisions about the future of nuclear power." In line with this approach, Schröder (2016) proposes that geological disposal be conceived as a "socio-technical experiment," thereby underlining both the experimental nature of this undertaking-in the sense that it concerns a "tentative procedure, adopted in uncertainty whether it will answer its purpose" (p. 689)—and the fact that both "the social" and "the technical" are inextricably linked and cannot

\footnotetext{
${ }^{10}$ Based on the closing date of the last nuclear power plants now envisaged in 2025 according to the Belgian nuclear phase-out policy.

11 This stepwise decision-making process is described in detail in an earlier version of the strategic Waste Plan (NIRAS/ONDRAF, 2011) which was drafted over the period 2009-2011 in line with a request from the Belgian government and in anticipation of the then forthcoming European Directive (cf. footnote 9). This Waste Plan was subsequently submitted to a mandatory strategic environmental impact assessment (SEA). Different options and alternatives were discussed (alongside geological disposal in a clay layer, temporary storage in anticipation of a better solution and a status quo option were considered) and public consultations were organized (e.g., mandatory public consultations in the framework of the SEA procedure, interdisciplinary stakeholder dialogues, and a public forum) (Parotte \& Delvenne, 2015). This was a key moment in the history of the Belgian HLW management program because it was the first time that HLW was explicitly and deliberately introduced into the arena of public and political debate. However, no formal commitment by the Belgian government was taken after the official publication. Instead, a recommendation by the ministers responsible stressed that research and development $(\mathrm{R} \& \mathrm{D})$ on the geological disposal option in poorly indurated clay should be continued, and that, at the same time, R\&D should be pursued in order to investigate alternatives that were not further analyzed in the waste plan (Parotte \& Delvenne, 2015). The current version of the Waste Plan only sets out a commitment to develop a phased process of stepwise decision-making, but contains no further details.
} 
be considered in isolation. This intricate connection (underscored by the hyphen in "socio-technical") also means that it actually no longer makes sense to speak of "the social" or "the technical" in a pure sense, since both of these categories are always already "contaminated" by the other.

How to understand this form of socio-technical mediation? The Foucauldian notion of "governmentality," developed in his course lectures in the period 1978-1980 (Foucault, 2007, 2008), can be usefully mobilized here, adding another figure of (political) technological mediation, which was overlooked by Dorrestijn (2012) (cf. Section 2). To give a concrete example of looking at socio-technical mediation through the lens of governmentality, the public consultations organized during the preparation of the earlier version of the Waste Plan are instructive. In particular, the public forum organized on behalf of NIRAS/ONDRAF by an independent charity (the King Baudouin Foundation) played a key role here (Parotte \& Delvenne, 2015). Disappointed by the small number of engaged citizens in the participatory dialogues organized earlier by NIRAS/ONDRAF itself, the agency decided to tackle the difficulty of "making society speak" by using the well-known participation format of a consensus conference. It involved a panel of randomly selected citizens-representative of the diversity of knowledge and opinion on nuclear waste and nuclear power in general-coming together for three weekends to arrive at consensual recommendations regarding the HLW management process. An open problem framing (responsive to whatever concerns are brought to the table by the representative citizens), the upholding of proper deliberative standards, and a consensual orientation are the key normative referents in consensus conferences. Durant (2009) explains the overriding concern for proper procedure and a consensual outcome by the dominance of STS scholars-who conceive of common values as social constructs emerging from common practices and processes-in the engineering of public participation. Jasanoff (2011, p. 625) adds that when STS scientists contribute to the development and implementation of policy processes, they tend to adopt an instrumentalist position, which prefers "...to concentrate on the most efficient means of meeting policymakers' proclaimed goals. That approach allows STS advisers to speak a language that policymakers understand ('public engagement' is itself such an example), a desirable enough aim in itself; but such discursive assimilation risks being historically and theoretically shallow, and it dangerously reduces the analytic distance between adviser and advice seeker, turning the former from energetic critic to pliant and unquestioning consultant."

Indeed, the recommendations of the public forum (Koning Boudewijnstichting, 2010) concerned mainly the preconditions for the HLW management process (with the geological disposal option as such not being questioned), which were formulated at a very general level. This outcome is not surprising: the consensus-driven nature of a public forum smooths out any tensions and disagreements in a search for the greatest common denominator (Szakolczai, 1994). However, the public forum did add some complementary requirements to the development of the geological disposal strategy, namely, that it should be reversible, retrievable, and controllable. According to one of our interviewees, this is because "...the idea of "passive safety' is difficult to understand for laypeople. This concept gives the impression that you don't want to monitor or control the safety of the repository. In the mind of 
laypeople, safety is usually connected to the idea that you can come back on previous decisions if something goes wrong. That is why the public forum also stressed a requirement like reversibility." The inclusion of different forms of flexibility (to wit: reversibility, ${ }^{12}$ retrievability, ${ }^{13}$ and recoverability ${ }^{14}$ )-i.e., the possibility to reconsider earlier decisions if necessary - in the prescriptions for the HLW management process is the most tangible influence of "the social" on "the technical." However, the Waste Plan also makes it very clear that these various forms of flexibility can only be adopted if they do not conflict with the ultimate goal of passive safety (NIRAS/ONDRAF, 2011, p. 136). Hence, societal concerns remain subsumed in the technical option that has been favored by NIRAS/ONDRAF for decades. To put it differently, societal adaptation does occur, but at the margins of the technical aspects (Parotte \& Delvenne, 2015) - i.e., adaptation occurs as long as it fits with the imaginary of forgetting the waste by implementing passive safety.

This modest impact of "the social" on "the technical" probably will not come as a big surprise to most political scientists and has been documented before in nuclear waste management practices (Blowers \& Sundqvist, 2010; Durant, 2009; Parotte \& Delvenne, 2015; Sundqvist \& Elam, 2010a, b). As observed by one of our interviewees (a social scientist involved as an observer in the public forum), between the second and the third weekend of the public forum, NIRAS/ONDRAF organized a visit to the underground laboratory in Mol. By the third weekend, it was then "somewhat surprising" to see how positive all participants were about the geological disposal option. This interviewee then proffered the conjecture that "a demonstration of safety - 'seeing it with your own eyes' - can be a powerful way to convince people." This is of course but one conjecture of socio-technical mediation, which should be further investigated. Nevertheless, on a more fundamental level, we contend that the Foucauldian notion of governmentality opens up an entire research agenda for analyzing the process of stepwise decision-making in HLW management in Belgium or elsewhere. Applied to our topic, the creation of "mini publics" (such as the one involved in the public forum), for instance, requires the concrete organization and implementation of a whole range of techniques-selection techniques, presentation techniques, argumentation techniques, conversation techniques, etc.- - which make it the object of choice for a Foucauldian analysis in terms of the modes of governmentality involved. The instrumentation of public action (in the sense that relevant publics will be "produced" or "convened" in function of the different stages of the decision-making process) should be studied in terms of a theorization of the particular relationship

\footnotetext{
12 That is, the possibility of removing waste packages (in the event a defect is noticed) in disposal galleries not yet sealed or backfilled, using the same (or similar) means by which they were placed in the repository.

13 That is, the possibility of removing waste packages (in the event a defect is noticed) in backfilled and sealed galleries, using, if appropriate, other means than those used initially to put the waste into the galleries. The operations the retrievability refers to assume that the physical integrity of the waste packages are still guaranteed.

14 That is, the ability to retrieve the waste when the integrity of the packages cannot be guaranteed anymore. Recoverability usually refers to an ultimate retrievability beyond the operational phase and beyond the phase of institutional control (e.g., mining of the waste packages to recover fuel).
} 
established between the governing agency (i.e., the organization setting the ground rules and providing the resources for particular public consultations) and the governed agency (i.e., the modalities of interaction the particular consultation mechanism allows for). Seen from a perspective of governmentality, each instrument of public consultation also embodies particular knowledge about the exercise of social power. In this sense, the socio-technical mediation is a specific government activity based on (implicit or explicit) theories about the right way to manage political relationships and the relationship to society. It is also an indicator of the particular regulatory problems that public action strives to solve at each stage of decision-making.

\section{State-Technical Mediation: Geological Disposal as a Technology for the Common Good}

So far, we have established the crucial role played by the imaginary of "forgettingby-not-showing" (based on an amended version of Dorrestijn's mediation by "technological determination") (Section 3), underpinned by techno-scientific mediation (Section 4), and of setting out a credible implementation process underpinned by socio-technical mediation (Section 5) in NIRAS/ONDRAF's overall strategy for positing geological disposal (and the concept of "passive safety") as a possible and preferable end point or "solution" for the problem of managing HLW in Belgium. However, as explained in the introduction, one fundamental remaining hurdle for starting the implementation of the geological disposal program is the approval of the Belgian government. Or in other words, NIRAS/ONDRAF is faced with the task of providing compelling reasons for Belgian decision-makers to decide in favor of geological disposal as soon as possible. Continuing our general line of investigation, NIRAS/ONDRAF has to talk the language of "state reason" (raison d'état), identified by Foucault as a fundamental dimension of governmentality (Foucault, 2007, pp. 236-238). According to Foucault, starting from the sixteenth century, a fundamental shift occurred in thinking about state government in the sense that models of state government no longer derived their ultimate justification from other models of governing resting on divine or natural laws. From then on, the strength of the state constitutes its own justification, with state reason referring to the (historically determined forms of) complex calculations and measurements of the different "forces" acting within a state that contribute to its overall strength. Factors such as wealth, resources, safety, and health of the population all contribute to a state's strength.

Adopting the Foucauldian perspective of state reason, it is instructive to analyze how the different considerations regarding the acceptability of HLW management options are translated into measurable and comparable units of "force." At the root of this translation lie the internationally accepted principles of radiation protection which were established initially by the International Commission of Radiation Protection (ICRP) in the recommendation of Publication 26 of 1977, and have over the years been further specified for different application contexts (Kermisch \& Depaus, 2018; Kermisch et al., 2016): 
- Justification implies that, when practices involving (potential) exposure to radiation are considered, the radiation detriment should be explicitly included in the process of choice. The detriment to be considered is not confined to that associated with radiation: it includes other detriments and the costs of the practice.

- Optimization implies that the magnitude of individual doses, the number of people exposed, and the likelihood of potential exposure must be kept as low as reasonably achievable, with due consideration for economic and social factors. In the ICRP publication dedicated to geological disposal of radioactive waste (ICRP, 2013), this principle has been further specified as follows: "The ICRP principle of optimisation of radiological protection when applied to the development and implementation of a geological disposal system has to be understood in the broadest sense [...] for enhancing the protective capabilities of the system and for reducing impacts (radiological and others)."

- Dose limits imply that in any case, the doses of exposition of the workers and the population are kept well below certain established regulatory limits.

The principles of justification and optimization are consequentialist in nature: they are concerned with a collective consideration of the pros and cons of the activities that result in exposure to ionizing radiation (justification) and minimizing that exposure within reasonably achievable limits (optimization). The principle of dose limitations is deontological in nature because it sets absolute individual limits on allowable levels of exposure to ionizing radiation and hence also serves as a criterion for the a priori exclusion of waste management methods that under normal operational conditions fail to respect these limits.

For deciding on acceptable HLW management options, NIRAS/ONDRAF operationalizes these principles using the ethical matrix method (Kermisch \& Depaus, 2018; Kermisch et al., 2016). Practically, an ethical matrix is a two-dimensional table which combines affected stylized stakeholders (e.g., "local communities," "society in general," "the environment," "on-site workers," and "waste producers") and moral values (e.g., "well-being," "informed consent," and "equity") in order to clarify the ethically relevant issues associated with options for managing HLW. The cells of the matrix are filled in with the moral issues related to each moral value and relevant to the different stakeholder categories. These morally relevant issues then serve as criteria for analyzing and comparing the options under scrutiny through the in-depth analysis of each ethically relevant issue. For instance, in Kermisch and Depaus (2018), a comparison is made between immediately opting in favor of geological disposal in a clay layer (which has been the focus of dedicated research over the last four decades) vs. a prolonged process that first analyzes other potential host layers before proceeding to the implementation of a geological repository. The authors come to the conclusion that the choice between these options boils down to a choice between favoring the safety of near-future generations (option 1) or favoring the safety of far-future generations (option 2) - a choice that, according to the authors, cannot be decided by ethical reasoning alone and hence is left to "politics." Hence, a strict separation is introduced between reasoning based on strict - and presumably universally applicable_decision rules (that decide between the priorities to be given to the different stylized stakes at play in the decision) and 
political reasoning based on decision criteria that are not further specified (but presumably cannot count on universal acceptance). However, this separation itself rests on a pragmatic political judgment that cannot itself be justified in terms of universal reason. ${ }^{15}$

Another important comment needs to be made with regard to this line of reasoning: the decision on HLW management is separated from the discussion about the past and future of nuclear energy in Belgium. This is the result of a clear division of tasks: NIRAS/ONDRAF, as the responsible organization for the management of radioactive wastes, is not mandated to make statements about the desirability of nuclear energy as such. However, the two issues cannot simply be separated from an ethical and political point of view. Today, the environmental movement is concerned (perhaps not entirely unjustly) that the global nuclear lobby would "breathe a sigh of relief" if a "solution" (even of a principial nature) to the nuclear waste problem were to be found (Darst \& Dawson, 2010). Moreover, the justification principle (cf. supra) also clearly states that waste management is an integral part of the practice that causes the waste (such as electricity production in nuclear power plants) and must therefore also be considered in decisions about that practice. The disconnect between the (discussion about) whether or not to use nuclear power and the management of nuclear wastes as a result of this choice is not only institutional in nature; more theoretically oriented reflections in the field of intergenerational ethics are equally affected. For instance, in a reflection on Belgian HLW management, the ethicist Axel Gosseries clearly states that “...we shall be selective. For example, the fact that uranium is a non-renewable resource raises similar intergenerational issues as those raised by fossil fuels. The exact contribution of nuclear energy to climate change, the connections between civilian and military uses of radioactive materials, as well as whether we should continue relying on nuclear energy at all are all set aside. What matters here is the qualitative nature of some of the intergenerational problems at stake, independently of the assessment of their quantitative importance" (Gosseries, 2005, p. 178).

Gosseries' restraint is not surprising. An interpretation of the justification principle that focuses on a utilitarian consideration of the costs and benefits (in a wide sense) of the use of nuclear power immediately raises the question of what then the common denominator might be for comparing these costs and benefits. How, for example, do the risks for future generations weigh up against the benefit we have derived from nuclear electricity production? The sharp distinction between the "useful" and the "useless" (and harmful) aspects of nuclear power (cf. Section 3) thus plays a constitutive role not only in practical terms, but also for ethical reasoning applied to the issue of HLW management. Furthermore, following the general gist of the Foucauldian project as a "critical ontology of the present" (Foucault, 1984), we can ask ourselves whether NIRAS/ONDRAF's position does not amount to a preclusion of the political option to critically analyze the history that has brought

\footnotetext{
15 Within the confines of the present article, we cannot provide a further detailed criticism. We will limit ourselves to raising one point: if, as is claimed by Kermisch and Depaus (2018), the "no harm" principle towards future generations has an overriding priority under the perspective of sustainable development, then surely option 2 (providing more safety for all generations roughly after the year 2200) should be preferred over option 1 (providing more safety for the generations up to the year 2200)?
} 
us to the "here and now" in order to actively shape our future freedom. The nuclear waste problem we are facing now is the result of past decisions, that much is clear. Interrogating ourselves about the ethos that has brought us to the current problem situation (i.e., the decision to use nuclear power and the history of the Belgian nuclear power program up to the present) and thinking about how we can relate to this ethos in view of the future represent a political option that is opened up by a Foucauldian line of questioning. However, this critical interrogation is quite simply excluded from view in the operationalization of ethics in the Belgian HLW management program. Hence, the need for adding the state-technical mediation based on raison d'état to Dorrestijn's repertoire of mediation figures to account for this result.

\section{Discussion and Conclusions}

Our main aim in this paper was to introduce a political questioning in mediation theory, in dialogue with an investigation of the HLW management program in Belgium. In contrast to the epistemological and normative ethics approaches, we showed how the power of scientific and moral arguments in favor of or against particular HLW management options is intrinsically linked with the temporal unfolding of a HLW management program, and the nuclear power program that produces the waste in the first place. Our approach should however not be misunderstood as an attempt to simply reject the previous philosophical analyses as unfounded. Such a strategy would still implicitly accept the basic terms in which the question is asked-i.e., the search for universally acceptable foundations underpinning claims of truth and legitimacy. The point is not so much to substantiate or refute the validity of a specific technological choice (in our case, geological disposal), but rather to expose the mediations at work from which the arguments in favor of geological disposal derive their claims for validity (in a scientific and moral sense).

Table 1 summarizes our findings. On a theoretical level, we built on previous insights derived from mediation theory (in particular the work of Verbeek and Dorrestijn), Foucault, and science and technology studies (in particular Jasanoff's work on socio-technical imaginaries). To properly introduce the political dimension of technological mediation, we modified Dorrestijn's figure of "technical determination of power relations" to better take into account the (literal and figurative) aspects of imagination, and complemented Dorrestijn's work on figures of technological mediation with the figures of techno-scientific mediation, and the inherently political figures of socio-technical and state-technical mediation, both based on Foucault's notion of governmentality. Our aim here was mainly programmatic: through our case analysis, we showed the importance of further developing mediation theory in a political direction, but we reserve a fuller theoretical treatment of this question for a later stage.

On a practical political level, the analysis carried out in this paper allows for a novel interpretation of HLW management, using the Belgian case as an example. It exposes the imagination of geological disposal as a "technological diagram of forgetting" - a diagram that allows for a strict distinction between the "useful" and "useless" (and harmful) dimensions of nuclear energy policy while it is maintained. 


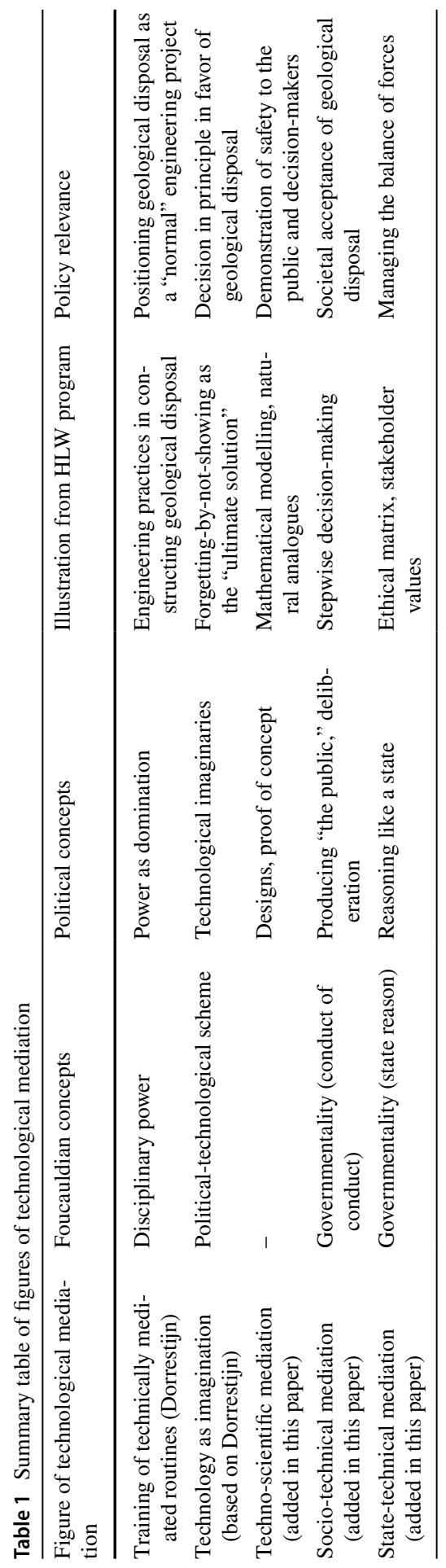


Without this imagination being put in place, talk of a "solution" to the problem of HLW management would simply be impossible, hence also the crucial importance for NIRAS/ONDRAF of a political decision in principle in favor of geological disposal. This imagination of forgetting is further underpinned by the techno-scientific mediation involved in positing geological disposal as the "ultimate solution" for the HLW problem and the socio-technical mediation implied by the actual implementation of the geological repository, with its focus on engineering practices (involving monitoring, testing, keeping records, etc.) and the stepwise decision-making processes (involving the activation of adequate 'publics') built around them. In this sense, the socio-technical mediation is a specific government activity based on (implicit or explicit) theories about the "right" way to manage political relationships and the relationship to society. Finally, in the state-technical mediation, a calculation of "forces" is enabled by positing objectified stakeholder categories and values and decision rules (based on international principles) for determining the best possible trajectory leading to the final closure of the repository. In sum, in Foucauldian terminology, an "apparatus of governmentality" is erected around the implementation of a geological disposal, requiring the strategic "stitching together" of a number of techniques drawing from the spheres of applied science, technology, and ethics.

This "stitching together" covers up possible fault lines, oppositions, and potential alternatives that are at odds with otherwise stable dominant constructions of what is considered to be the "best" option for managing HLW. In this sense, our philosophical reading of the Belgian HLW management also has relevance for those seeking to speak "truth to power." According to our reading, NIRAS/ONDRAF's push for the realization of a geological disposal on Belgian territory appears as one perspective on the ethical problem situation we are facing - and while valid, it certainly is not the only possible one. Of course, future generations have the right to be adequately protected against the risks of radiation. And let us be clear, certainly for part of the already existing nuclear waste-namely, the waste that has already been vitrified - there is currently no other conceivable ultimate destination besides geological disposal. After all, this vitrification was done specifically with a view to placing the waste packages in a geological repository and is irreversible in practical terms. In the absence of other options, geological disposal may therefore ultimately be the only way for us to deal with nuclear waste in a technological way-this is as far as we can go along with NIRAS/ONDRAF's reasoning. But NIRAS/ONDRAF's exclusively technological framing of geological disposal as a technical "solution" to the waste problem occludes the inherently political dimension of the HLW management program. In explicit recognition of this political dimension (and especially the political effects of framing), and given the current state of affairs, we would therefore propose to speak of "geological disposition" as an arrangement or plan for disposing of the HLW, instead of "geological disposal" as an "ultimate solution"i.e., emplacement without intent to retrieve-to describe the desired objectives of nuclear waste management programs. Furthermore, the inherent link between "disposal" and "forgetting" also has a connotation of surrendering one's responsibility, whereas "disposition" stresses one's continuous responsibility. Given the current state of the management process, it may furthermore be appropriate to consider strategies for extending the time between emplacement of waste and closure of a 
repository. A choice (even "in principle") in favor of a geological disposal means a first step towards forgetting nuclear waste (and the practice that led to this nuclear waste), while a Foucauldian questioning creates an opening towards other perspectives on the future of nuclear waste management.

Acknowledgements We especially wish to thank the interviewees who participated in the research for their valuable time and insights. We also thank Mandi Astola and Shelly Tsui as well as two anonymous reviewers for their insightful comments on an earlier version of this paper.

Funding The empirical research performed for this paper was part of the SCALINGS ("Scaling up Cocreation: Avenues and Limits for Integrating Society in Science and Innovation research project"), funded by the European Union's Horizon 2020 research and innovation program under Grant Agreement 788359.

Open Access This article is licensed under a Creative Commons Attribution 4.0 International License, which permits use, sharing, adaptation, distribution and reproduction in any medium or format, as long as you give appropriate credit to the original author(s) and the source, provide a link to the Creative Commons licence, and indicate if changes were made. The images or other third party material in this article are included in the article's Creative Commons licence, unless indicated otherwise in a credit line to the material. If material is not included in the article's Creative Commons licence and your intended use is not permitted by statutory regulation or exceeds the permitted use, you will need to obtain permission directly from the copyright holder. To view a copy of this licence, visit http://creativecommons.org/licen ses/by/4.0\%.

\section{References}

Barthe, Y. (2009). Framing nuclear waste as a political issue in France. Journal of Risk Research, 12(78), 941-954. https://doi.org/10.1080/13669870903126119

Behrent, M. C. (2013). Foucault and technology. History and Technology, 29(1), 54-104. https://doi.org/ $10.1080 / 07341512.2013 .780351$

Bensaude Vincent, B., \& Loeve, S. (2018). Toward a philosophy of technosciences. In S. Loeve, X. Guchet, \& B. Bensaude Vincent (Eds.), French philosophy of technology: Classical readings and contemporary approaches (pp. 169-186). Springer International Publishing. https://doi.org/10. 1007/978-3-319-89518-5_11.

Bergen, J. P., \& Verbeek, P.-P. (2020). To-do is to be: Foucault, Levinas, and technologically mediated subjectivation. Philosophy \& Technology. https://doi.org/10.1007/s13347-019-00390-7.

Blowers, A., \& Sundqvist, G. (2010). Radioactive waste management-technocratic dominance in an age of participation. Journal of Integrative Environmental Sciences, 7(3), 149-155. https://doi.org/10. 1080/1943815X.2010.509042

Darst, R., \& Dawson, J. I. (2010). Waiting for the nuclear renaissance: Exploring the nexus of expansion and disposal in Europe. Risk, Hazards \& Crisis in Public Policy, 1(4), 47-80. https://doi.org/10. 2202/1944-4079.1047

Davis, M. (2019). Temporal limits on what engineers can plan. Science and Engineering Ethics, s11948019-00124-0. https://doi.org/10.1007/s11948-019-00124-0.

Dorrestijn, S. (2012). Technical mediation and subjectivation: Tracing and extending Foucault's philosophy of technology. Philosophy \& Technology, 25(2), 221-241. https://doi.org/10.1007/ s13347-011-0057-0

Durant, D. (2009). Radwaste in Canada: A political economy of uncertainty. Journal of Risk Research, 12(7-8), 897-919. https://doi.org/10.1080/13669870903126127

Foucault, M. (1982). The subject and power, afterword. In H. Dreyfus, \& P. Rabinow (Eds.), Michel Foucault: Beyond structuralism and hermeneutics (pp. 208-226). University of Chicago Press.

Foucault, M. (1984). What is enlightenment? In P. Rabinow (Ed.), The foucault reader. Pantheon Books.

Foucault, M. (1990). The care of the self: The history of sexuality (vol. 3). Penguin Books.

Foucault, M. (1991). Discipline and punish. The birth of the prison. Penguin Books. 
Foucault, M. (1992). The use of pleasure: The history of sexuality (vol. 2). Penguin Books.

Foucault, M. (2007). Security, territory, population. In M. Senellart (Ed.), Lectures at the College de France 1977-1978. Palgrave Macmillan.

Foucault, M. (2008). The birth of biopolitics. In M. Senellart (Ed.), Lectures at the College de France 1978-1979. Palgrave Macmillan.

Foucault, M. (2012). On the Government of the Living. In M. Senellart (Ed.), Lectures at the College de France 1979-1980. Picador.

Gerrie, J. (2003). Was Foucault a philosopher of technology? Techné: Research in Philosophy and Technology, 7(2), 66-73.

Gosseries, A. (2005). Radiological Protection and Intergenerational Justice. In G. Eggermont, \& B. Feltz (Eds.), Ethics and radiological protection (pp. 167-195). Academia-Bruylant.

International Atomic Energy Agency (2011). Geological disposal facilities for radioactive waste, IAEA safety standards series No. SSG-14, IAEA, Vienna.

International Atomic Energy Agency. (2018). Status and trends in spent fuel and radioactive waste management. International Atomic Energy Agency (IAEA).

International Commission on Radiological Protection. (1997). Radiological protection policy for the disposal of radioactive waste. ICRP Publication 77. International Commission on Radiological Protection (ICRP). Pergamon.

International Commission on Radiological Protection. (2013). Radiological protection in geological disposal of long-lived solid radioactive waste. ICRP Publication 122. International Commission on Radiological Protection (ICRP) Annals of the ICRP, 42(3), 1-57

Jasanoff, S. (2011). Constitutional moments in governing science and technology. Science and Engineering Ethics, 17(4), 621-638. https://doi.org/10.1007/s11948-011-9302-2

Jasanoff, S., \& Kim, S.-H. (2009). Containing the atom: Sociotechnical imaginaries and nuclear power in the United States and South Korea. Minerva, 47(2), 119-146. https://doi.org/10.1007/ s11024-009-9124-4

Kermisch, C., \& Depaus, C. (2018). The strength of ethical matrixes as a tool for normative analysis related to technological choices: The case of geological disposal for radioactive waste. Science and Engineering Ethics, 24(1), 29-48. https://doi.org/10.1007/s11948-017-9882-6

Kermisch, C., Depaus, C., \& Labeau, P.-E. (2016). A contribution to the analysis of equity associated with high-level radioactive waste management. Progress in Nuclear Energy, 92, 40-47. https://doi. org/10.1016/j.pnucene.2016.05.010

Kermisch, C., \& Taebi, B. (2017). Sustainability, ethics and nuclear energy: Escaping the dichotomy. Sustainability, 9(3), 446. https://doi.org/10.3390/su9030446

Koning Boudewijnstichting. (2010). Publieksforum 'Hoe beslissen over het langetermijnbeheer van hoogradioactief en langlevend afval?’ Eindrapport (p. 33). Koning Boudewijnstichting.

NIRAS/ONDRAF. (2011). Afvalplan voor het langetermijnbeheer van geconditioneerd hoogradioactief en/of langlevend afval en overzicht van verwante vragen. Rapport NIROND 2011-02 N, Brussels.

OECD-NEA. (1995). The environmental and ethical basis of geological disposal of long-lived radioactive waste: A collective opinion of the radioactive waste management committee of the nuclear energy agency. Organisation for Economic Co-operation and Development Nuclear Energy Agency (OECD-NEA).

OECD-NEA. (2007). Regulating the long-term safety of geological disposal. Towards a common understanding of the main objectives and bases of safety criteria. Organisation for Economic Co-operation and Development Nuclear Energy Agency (OECD-NEA).

Parotte, C., \& Delvenne, P. (2015). Taming uncertainty: Towards a new governance approach for nuclear waste management in Belgium. Technology Analysis \& Strategic Management, 27(8), 986-998. https://doi.org/10.1080/09537325.2015.1044429

Poirot-Delpech, S., \& Raineau, L. (2016). Nuclear waste facing the test of time: The case of the French deep geological repository project. Science and Engineering Ethics, 22(6), 1813-1830. https://doi. org/10.1007/s11948-015-9739-9

Schröder, J. (2016). Geological disposal of radioactive waste: A long-term socio-technical experiment. Science and Engineering Ethics, 22(3), 687-705. https://doi.org/10.1007/s11948-015-9650-4

Schröder, J., Bergmans, A., \& Laes, E. (2015). Advanced research, lagging policy. In A. Brunnengräber, M. R. Di Nucci, A. M. Isidoro Losada, L. Mez, \& M. A. Schreurs (Eds.), Nuclear waste governance: An international comparison (pp. 141-155). Springer Fachmedien. https://doi.org/10.1007/ 978-3-658-08962-7_6. 
Shrader-Frechette, K. S. (1993). Burying uncertainty: Risk and the case against geological disposal of nuclear waste. University of California Press.

Silvast, A., Laes, E., Abram, S., \& Bombaerts, G. (2020). What do energy modellers know? An ethnography of epistemic values and knowledge models. Energy Research \& Social Science, 66, 101495. https://doi.org/10.1016/j.erss.2020.101495

Solomon, B. D., Andrén, M., \& Strandberg, U. (2010). Three decades of social science research on highlevel nuclear waste: Achievements and future challenges. Risk, Hazards \& Crisis in Public Policy, 1(4), 12-46. https://doi.org/10.2202/1944-4079.1036

Sundqvist, G., \& Elam, M. (2010a). Public involvement designed to circumvent public concern? The "participatory turn" in European nuclear activities. Risk, Hazards \& Crisis in Public Policy, 1(4), 203-229. https://doi.org/10.2202/1944-4079.1046

Szakolczai, A. (1994). Thinking beyond the east-west divide: Foucault, Patocka, and the care of the self. Social Research, 61(2), 297-323. JSTOR.

Taebi, B. (2012). Intergenerational risks of nuclear energy. In S. Roeser, R. Hillerbrand, P. Sandin, \& M. Peterson (Eds.), Handbook of risk theory: Epistemology, decision theory, ethics, and social implications of risk (pp. 295-318). Springer Netherlands. https://doi.org/10.1007/978-94-007-1433-5_12.

Taebi, B., \& Kloosterman, J. L. (2008). To recycle or not to recycle? An intergenerational approach to nuclear fuel cycles. Science and Engineering Ethics, 14(2), 177-200. https://doi.org/10.1007/ s11948-007-9049-y

Tondel, M., \& Lindahl, L. (2019). Intergenerational ethical issues and communication related to highlevel nuclear waste repositories. Current Environmental Health Reports, 6(4), 338-343. https://doi. org/10.1007/s40572-019-00257-1

Verbeek, P.-P. (2011). Moralizing technology: Understanding and designing the morality of things. University of Chicago Press.

Verbeek, P. P. (2013). Resistance is futile: Toward a non-modern democratization of technology. Techné: Research in Philosophy and Technology, 17(1), 72-92. https://doi.org/10.5840/techne20131715

Publisher's Note Springer Nature remains neutral with regard to jurisdictional claims in published maps and institutional affiliations. 